\title{
A review of common parameters and descriptors used in studies of the impacts of heavy metal pollution on marine macroalgae: identification of knowledge gaps and future needs
}

\author{
Giulia Burle Costa, 2* (1), Gabrielle Koerich ${ }^{1,2}$ (D), Bruna de Ramos ${ }^{1,3}$ (), Fernanda Ramlov ${ }^{4}$ (), Begoña Martínez- \\ Crego $^{5}$ (D), Monya M. Costa $^{5}$ (D), Dora Jesus ${ }^{5}$ (D), Rui O.P. Santos ${ }^{5}$ (i) and Paulo A. Horta Jr. ${ }^{1,2}$ (1)
}

Received: February 29, 2020

Accepted: June 1, 2020

\begin{abstract}
This study presents a systematic review to assess the main similarities and gaps in efforts to evaluate the impacts of heavy metals on benthic marine seaweeds. A total of 91 studies were compiled, the main parameters (abiotic, biological, ecotoxicological, and heavy metals) and descriptors of which were evaluated by quantitative and qualitative analyses. Our results indicate the importance of diversifying searches by including different languages (i.e. English, Portuguese and Spanish). Most of the studies were field characterizations, with few abiotic parameters and/or seasonality evaluations being employed. In contrast, the assessment of ecotoxicological parameters was highly frequent, which seems incoherent considering the absence of data to support the use of these results in biomonitoring applications. The genera Sargassum, Ulva and Enteromorpha were widely studied worldwide, apart from a small fraction of studies assessing higher levels of biological organization. Moreover, the use of different parameters and descriptors by the evaluated studies precludes making conclusive or reliable comparisons. These findings highlight the importance of greater efforts to construct a concise baseline of knowledge using similar parameters so that global evaluations of the impacts of heavy metals on photosynthetic organisms can be undertaken.
\end{abstract}

Keywords: coastal management, heavy metal impacts, parameter replication efforts, pollution descriptors, systematic literature review

\section{Introduction}

Among anthropogenic disturbances, marine pollution is a serious issue worldwide as it alters the physical and chemical properties of seawater, with varied impacts in marine organisms (Gattuso et al. 2015; Lawes et al. 2016). A variety of substances is introduced in marine coastal waters, but heavy metals are one of the substances more widely studied. This is a result of this class of pollutants

1 Laboratório de Ficologia, Departamento de Botânica, Universidade Federal de Santa Catarina, 88049-900, Florianópolis, SC, Brasil

2 Programa de Pós-Graduação em Ecologia, Universidade Federal de Santa Catarina, 88049-900, Florianópolis, SC, Brasil

3 Programa de Pós-Graduação em Gerenciamento Costeiro, Universidade Federal do Rio Grande, 96203-900, Rio Grande do Sul, RS, Brasil

4 Laboratório de Morfogênese e Bioquímica Vegetal, Universidade Federal de Santa Catarina, 88049-900, Florianópolis, SC, Brasil

5 Marine Plant Ecology Research Group, Algarve University, Centre of Marine Sciences, University of Algarve, Campus Gambelas, 8005-139, Faro, Portugal

* Corresponding author: giuliaburle@gmail.com 
being highly prevalent in marine waters, and of the diverse origins of heavy metals in human activities (e.g. metallurgy, petroleum extraction, mining ores, industrial processes) or daily products (especially the ones related to the technological industry, such as batteries, agricultural inputs and pesticides) (Wang et al. 2013).

Metallic elements are naturally available in marine waters, and in small weight fractions (from micrograms to milligrams), they are important as nutrients for primary producers (Nagajyoti et al. 2010; Blaby-Haas \& Merchant 2017; Iluz et al. 2017). However, high concentrations of heavy metals induce toxicological effects, with declines in environmental quality caused by oxygen depletion and disruption of biogeochemical cycles (Nikinmaa 2013; Gao et al. 2017). Benthic producers, represented by seagrasses and seaweeds, are affected by the presence of contaminants due to changes in the mechanism of nutrient uptake and changes in the physicochemical characteristics of seawater. Heavy metals compete with nutrients for the cellular mechanisms of transport, reducing the seaweeds' nutrient uptake capacity (Wang \& Dei 2001; Lambers et al. 2008; Contreras-Porcia et al. 2017). In turn, the accumulation of heavy metals in benthic producers is also mediated by temperature and $\mathrm{pH}$, as a result of changes in chemical forms and the availability of metals to biological interactions (Peterson et al. 1984; Zeng et al. 2015; Contreras-Porcia et al. 2017). The combination of toxicity and stress then leads to changes in community's structure, through the loss of key foundation species, resulting in limited habitat availability, loss of functional diversity and compromising ecosystem's functioning (Sales et al. 2011; Sánchez-Quiles et al. 2017).

Seaweeds can change their physiology and morphology in response to environmental changes as a mechanism to improve resistance in adverse conditions. These organisms are recognized for their ability to sequester and immobilize heavy metals in cellular structures, such as vacuoles and cell walls (Contreras-Porcia et al. 2017). Their ability to accumulate these elements results in higher concentrations in tissues, and when the entire trophic chain is evaluated, the accumulated impacts could be amplified through higher trophic levels (Torres et al. 2008; Nikinmaa 2013). As a result of these properties, seaweeds are regarded as both bioindicators of environmental quality as well as biomonitors of processes of changes (Chakraborty et al. 2014). At the assemblage level, species composition reflects the spatial and temporal intensity of anthropogenic disturbances, as the effects of toxicity are reflected in the selection of tolerant organisms. Thus, algal diversity is modified, which consequently impacts ecosystem functioning.

Throughout recent decades, the anthropogenic impacts from local to global scales indicate an increase in the intensity and frequency of extreme disturbances. Similarly to climate change, where extreme events of heatwaves and cold spells are more frequent since the beginning of the $20^{\text {th }}$ century (Easterling et al. 2000), the occurrence of extreme events of pollution has also been increasing in different regions and systems (Arenas-Sánchez et al. 2016; Zhang et al. 2017; Carmo et al. 2017). The surge in environmental disasters is the result of increasing extractions and transformations of mining ores for different technological purposes, elevating the deposition rates of metallic wastes in the environment. Chronic pollution is also observed in coastal ecosystems, with a regular and constant influx of small amounts of pollutants that can bioaccumulate in organisms able to survive in these specific environmental conditions (Olivares et al. 2016). However, acute pollution caused by extreme events, such as mining disasters, are responsible for depositing very high concentrations of metals in coastal waters in a short period of time. Elements such as arsenic (As), cadmium (Cd), cobalt $(\mathrm{Co})$, chromium $(\mathrm{Cr})$, copper $(\mathrm{Cu})$, iron $(\mathrm{Fe})$, mercury $(\mathrm{Hg})$, manganese $(\mathrm{Mn})$, nickel $(\mathrm{Ni})$, lead $(\mathrm{Pb})$, and zinc $(\mathrm{Zn})$ are the most abundant and frequent in mining waste (Olivares et al. 2016; Segura et al. 2016). The effects of heavy metals are primarily studied in the context of accidents, precisely because of the high number of elements present in the waste and the short time of their deposition (Hatje et al. 2017).

Nowadays, the extent of metallic pollution impacts in marine producers is poorly understood. Sánchez-Quiles et al. (2017) made a review of the occurrence of disturbances by heavy metal pollution in macroalgae and seagrass beds around the world. Their results showed a large number of records of metallic impacts in regions such as Europe, India and United States. Unfortunately, the study has no information of such impacts in the South Atlantic. Apart from the recent disasters in the Brazilian coastal zone, such as the massive spill of mining tailings (Hatje et al. 2017), no previous records of heavy metals' impacts could be found for this marine region in past reviews.

Additionally, the main parameters used to describe heavy metals' impacts on seaweeds are of a diverse variety of analyses (i.e. biochemical, morphological, and physiological analyses) (Davis et al. 2003; Torres et al. 2008; Harley et al. 2012; Contreras-Porcia et al. 2017), conducted in the field and at in vitro laboratory experiments. However, these results are isolated or do not consider interactions between other physical or chemical parameters (Cardoso et al. 2008; Wernberg et al. 2011; Nikinmaa 2013). In a recent study, García-Seoane et al. (2018) exhaustively reviewed the methodologies adopted in different studies to assess the use of macroalgae as environmental biomonitors of pollution. The authors found in the studies a series of divergences in sampling and biomass preparation for posterior analyses, reinforcing the need of an accurate standardization in methods to improve the comparative strength of all obtained results.

Considering the current state of knowledge about the impacts of heavy metal pollution in marine seaweeds, the main objective of the present review is to systematically analyze the similarity of methods and biological models 
employed by studies to evaluate these impacts, seeking to improve the comparative strength between the observed effects, and recommend the use of similar descriptive parameters worldwide. Herewith, the true comparative potential of the database constructed in this study is inferred, and the main gaps in use of parameters are identified. Moreover, identifying key cosmopolitan seaweed groups worldwide will allow the evaluation of impacts in different ecosystems, as well as the possibility of monitoring based on similar responses under similar stress conditions. Lastly, identifying the distribution of studies, the efforts in using similar parameters across studies, and the main biological models used is also relevant to discuss the sharing of information about the impacts of heavy metals in marine waters on seaweeds. Gaps in dissemination of scientific information can induce misinterpretations or underestimate the importance of using certain descriptive parameters in studies, reducing the comparative strength between them. It is extremely important to evaluate the extent of research efforts for a better selection of monitoring parameters to measure the true damage of metallic elements in biological systems.

\section{Materials and methods}

We provide a systematic review of literature data following the methodology for bibliographical surveys recommended by Sampaio \& Mancini (2007). Searches were performed in Google Scholar (https://scholar.google. com.br), Science Direct (https://www.sciencedirect.com/), the Scientific Electronic Library Online (http://www.scielo. $\mathrm{br} /$ ), and the Brazilian CAPES Periodic Portal (http://www. periodicos.capes.gov.br/) databases. The selection of these databases considered open and free access to articles in Brazilian universities. Web of Science database was not used considering the assumptions adopted in our literature search methodology, and the fact that Scholar Google covers the majority of publications indexed in the Web of Science Database (Martín-Martín et al. 2018).

Peer-reviewed articles were selected from journals included in the Science Citation Index (SCI), including new journals without impact factors in the 2018 Journal Citation Reports (Clarivate Analytics 2018). Data published in books, thesis, scientific notes, conference proceedings and reports of institutional pages were not included in our database. The search was restricted to papers published between 2000 and 2017, to cover the publications related to the Millennium Ecosystem Assessment, an Organization that since 2001 has highlighted anthropogenic pollution as a source of impacts on marine systems with increasing severity over the last century (MEA 2005).

Selection of articles was based on research keywords included in the title and/or abstract and/or in manuscript keywords. The primary keywords searched were trace metals, heavy metals, seaweeds, and macroalgae. The following secondary keywords were coastal pollution, coastal impacts, marine pollution, coastal marine water, physiology, morphology, toxicology, ecotoxicology and anthropic impacts, which were included to expand the power of the search. Successive searches were done by inserting each primary and one secondary keyword by pairs in the search field with a total of 45 combinations. All keywords were also used three times, first in English as the main scientific language. Thereafter, we repeated the search with keyword combinations in Portuguese and Spanish, considering the possible limitation of scientific accessibility in English in developing countries (reviewed by Sánchez-Quiles et al. 2017). After the exclusion of duplicates among the selected databases, a total of 91 studies were compiled (see List S1 in supplementary material).

Information regarding the studies' effort to evaluate impacts and the parameters used are detailed in Table 1 . The studies' effort was divided in five categories: study location, and abiotic, biological, heavy metal and ecotoxicological parameters. For each proposed category, parameters used to assess the effect of heavy metals were documented. The compiled qualitative information was transformed for statistical analyses. To calculate the relative frequency (number or percentage of studies) of each parameter in each study within a category, data was transformed to binary (absence - 0, presence -1). Qualitative data such as seasonality and climatic zone were transformed to ordinated data, with numbers attributed to categories of each parameter. Graphical representations of qualitative data were obtained from transformed binary or ordinal data. The qualitative nominal parameters (i.e. county from study location category and organisms' genera list from biological parameters) were represented in word cloud graphs. Graphs were constructed using the packages ggplot2 and wordcloud (version 2.6) from R software (R Development Core Team 2018). In the wordcloud graphs, size and thickness of words are proportional to frequency of citations of studies composing the database. All graphics were exported through the Adobe Illustrator software.

After the initial evaluation of the raw data $(n=91)$, the results of the most used biological models were separated, and all previously described analyses and graphical representations were repeated for them. Considering the presence of a wide range of species with low individual frequency across studies, we chose to conduct analyses at the genus level for taxa with high representation.

\section{Results and discussion}

\section{Parameters of research dissemination: study location and abiotc parameter categories}

Selected articles were from 45 different journals, in a wide range of journal impact factors (JIF), according to Journal Citation Report (Clarivate Analytics 2018). The 


\section{A review of common parameters and descriptors used in studies of the impacts of heavy metal pollution on marine macroalgae: identification of knowledge gaps and future needs}

range of JIFs are represented by a histogram (Fig. 1A). Four articles did not have JIF in the 2018 JCR (new journals), while other four publications presented IF higher than 6.00. The higher frequency of publications was in IF between 2.00 to 2.99 , with 24 articles (21.84\%) (Fig. 1A).

Among the most cited journals, articles with more citations were published in Marine Pollution Bulletin (eigth), followed by Protoplasma (six), Bulletin of Environmental Contamination and Toxicology, Environmental Monitoring and Assessment and Journal of Applied Phycology (five each). The citation frequency in journals $(n=91)$ is presented as a word cloud in Figure 1B.

Our database contains data produced in all continents, with the Americas (29), Europe (25) and Asia (23) being the most representative in number of studies (Fig. 2A). Antarctica presented the lowest occurrence of studies related to heavy metals' impacts, with only two articles. In total, 34 countries were represented, although fifty percent of studies were concentrated in only seven of them: Brazil (14), Chile (seven), India and Mexico (six each), England (five), and Australia and Egypt (four each) (Tab. 2). This result indicates that while we attained our aim in covering the often less represented regions, the most studied regions were misrepresented in the previous review of Sánchez-
Quiles et al. (2017), and in widely used databases such as Web of Science.

The distribution between continents can be related to the elevated number of Universities and Scientific Research Centers in Europe, North America and Asia. According to the Scientific Journal Rankings (SCImago 2018), the ten best universities worldwide are located in North America (USA and Canada), Europe (UK, Germany, France, Italy and Spain) and Asia (China, Japan and India). However, the high frequency of studies in Brazil and the representation of Latin American countries in the present study is pertinent, as it contrasts with previous assumptions of North America universities importance in this field. This result reflects the importance of database selection in the first step of literature surveys, when the objective is defined. Similarly, we can compare present results with GarcíaSeoane et al. (2018), where authors also observed a higher representativity of Asia, Latin America and Oceania when searching in databases such as Scopus. Future discussions about the influence of algorithms and search engine indexing in literature surveys should be stimulated to avoid biases and promote broader dissemination of scientific information.

The traditional database Web of Science indexes articles in English, as it is the current scientific language, and many ranked publications are not provided as open

Table 1. Hierarchical organization of data compiled from the literature related to the efforts in evaluating the impacts of heavy metals in marine seaweeds. For each efforts' category, applied parameters collected and the statistical characteristic of qualitative/ quantitative data are indicated. The accessed information column shows the information explored by each category.

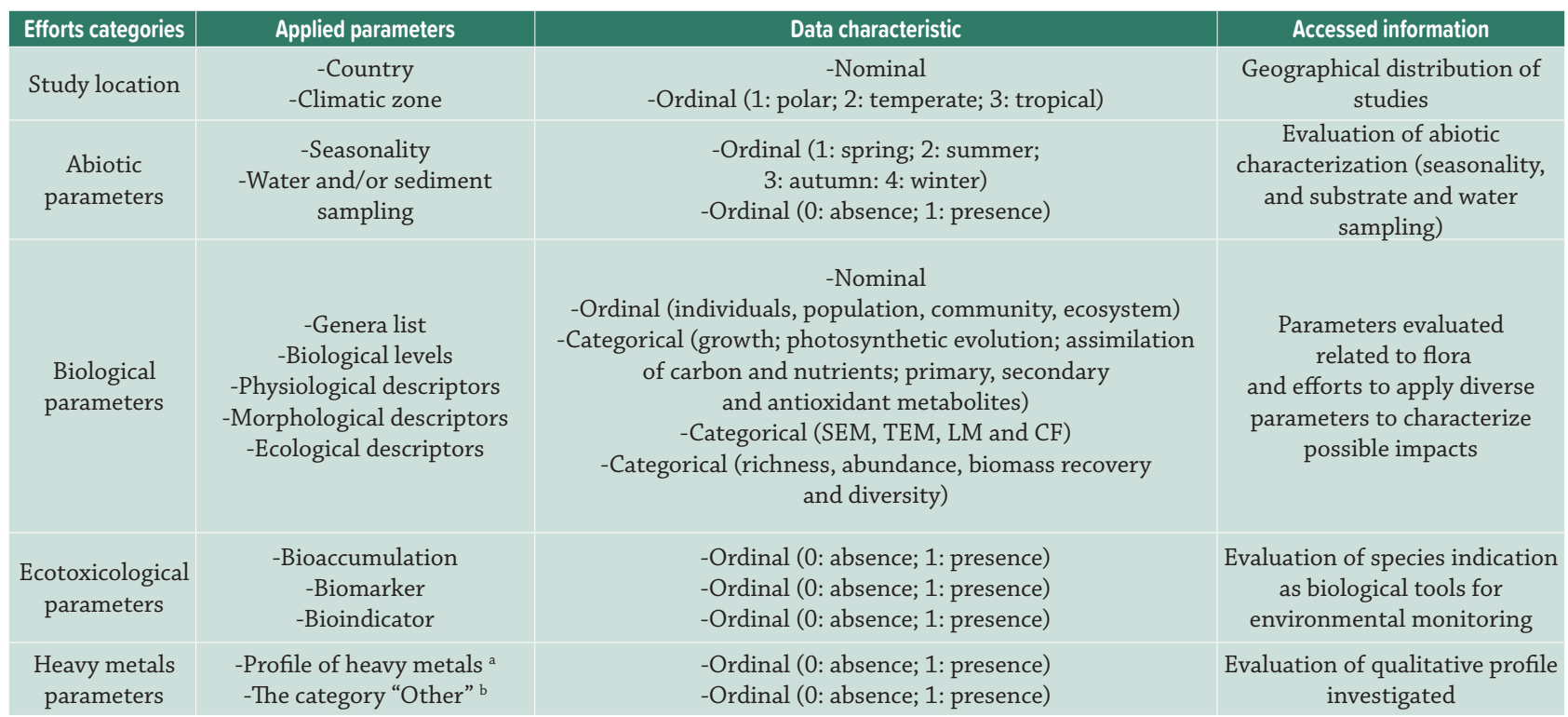

a The profile of metals includes the major citations in the titles and/or abstracts and/or keywords during the literature selection: aluminum (Al), arsenic (As), cadmium ( $\mathrm{Cd})$, copper $(\mathrm{Cu})$, iron (Fe), mercury ( $\mathrm{Hg})$, manganese (Mn), lead (Pb), and zinc ( $\mathrm{Zn})$, and compiled data refers to doses in biomass measurement;

b The category "Other" includes the diverse other small frequencies of metals citation founded in studies, such as calcium (Ca), chromium $(\mathrm{Cr})$, cobalt $(\mathrm{Co})$, gold $(\mathrm{Au})$, nickel $(\mathrm{Ni})$, magnesium $(\mathrm{Mg})$, molybdenum (Mo), and vanadium $(\mathrm{V})$, and compiled data refers to doses in biomass measurement;

Abbreviations: SEM: Scanning Electron Microscopy; TEM: Transmission Electron Microscopy; LM: Light Microscopy; and CF: Confocal Microscopy. 
access, limiting the access and dissemination of full articles worldwide. The proposed inclusion of platforms, such as Google Scholar, Scielo and CAPES Portal, is important to cover South America research. This inclusion during the literature search allowed a linguistic diversification (i.e. English, Portuguese and Spanish languages), which highly influenced the ranking of results in the search. Linguistic diversification returned articles that were not present in lists available when the keywords were searched exclusively in English. This observation has been presented and discussed by Martín-Martín et al. (2018). Those authors compared the divergences between different databases and similarities of

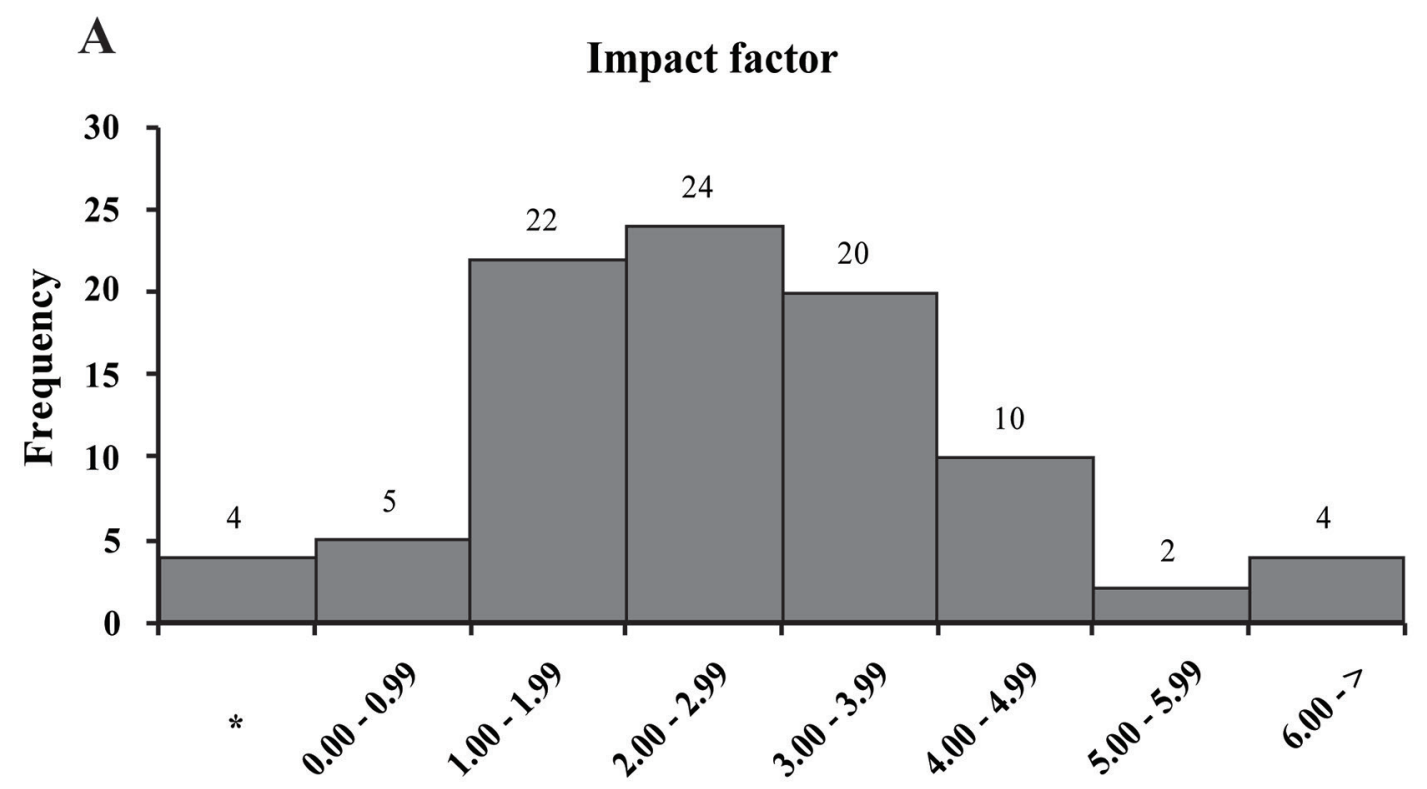

B

\section{Environmental International}

\section{Bulletin of Environmental Contamination Toxicology} Marine Pollution Bulletin

\section{Environmental Pollution}

Science of the Total Environment

\section{Journal of Applied Phycology}

Ecotoxicology and Environmental Safety

Chemistry and Ecology

\section{Environmental Monitoring and Assessment}

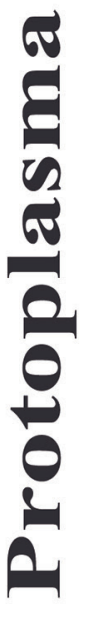

Figure 1. A. Histogram of the distribution of impact factors according to the Journal Citation Reports (JCR 2018). The symbol $\left({ }^{*}\right)$ indicates journals not indexed with Impact Factor in the current year. B. Word cloud of citations frequency for journals where selected studies were published. Letters size and line strength indicate the proportional frequency of each journal. 
search mechanisms among them. They highlight that Google Scholar's data surpasses Web of Science's and has the power to include a higher percentage of studies in non-English languages and with lower citation indices. Therefore, our database was able to fill gaps in scientific dissemination, attaining the objectives of the proposed review. However, it is important to highlight that the present database is composed exclusively of articles published in English as result of the defined article selection criteria.
Regarding climate zones, the highest incidence of studies was found in temperate zones (65 articles, $71.43 \%$ ), followed by tropical areas (18 articles, $19.78 \%$ ). The polar areas were underrepresented, with only 3 articles (3.30\%) (Fig. 2B). This highlights a gap in our understanding, and concentrated efforts to fill this gap must be done especially considering Antarctica and Arctic's importance in global ecological processes. Considering global changes such as ocean warming and acidification, the immobilized pollutants

A

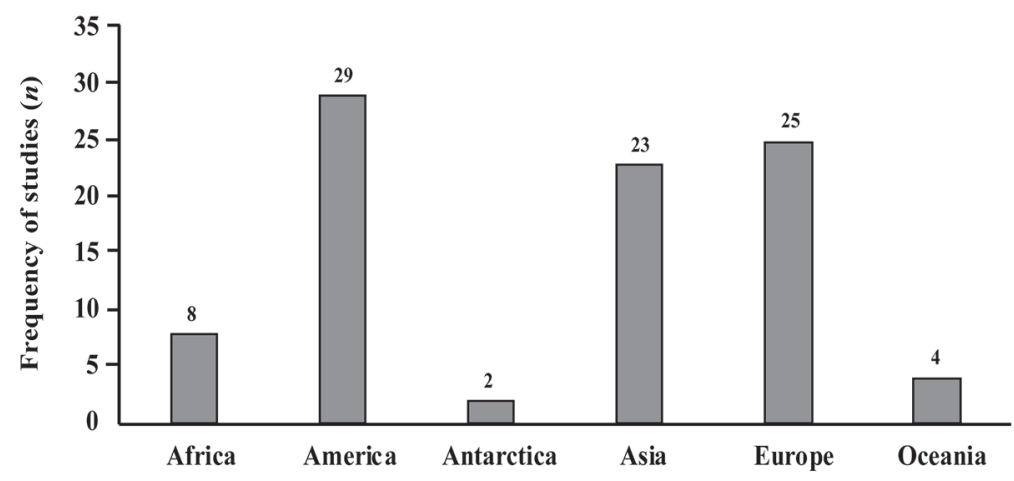

Continents
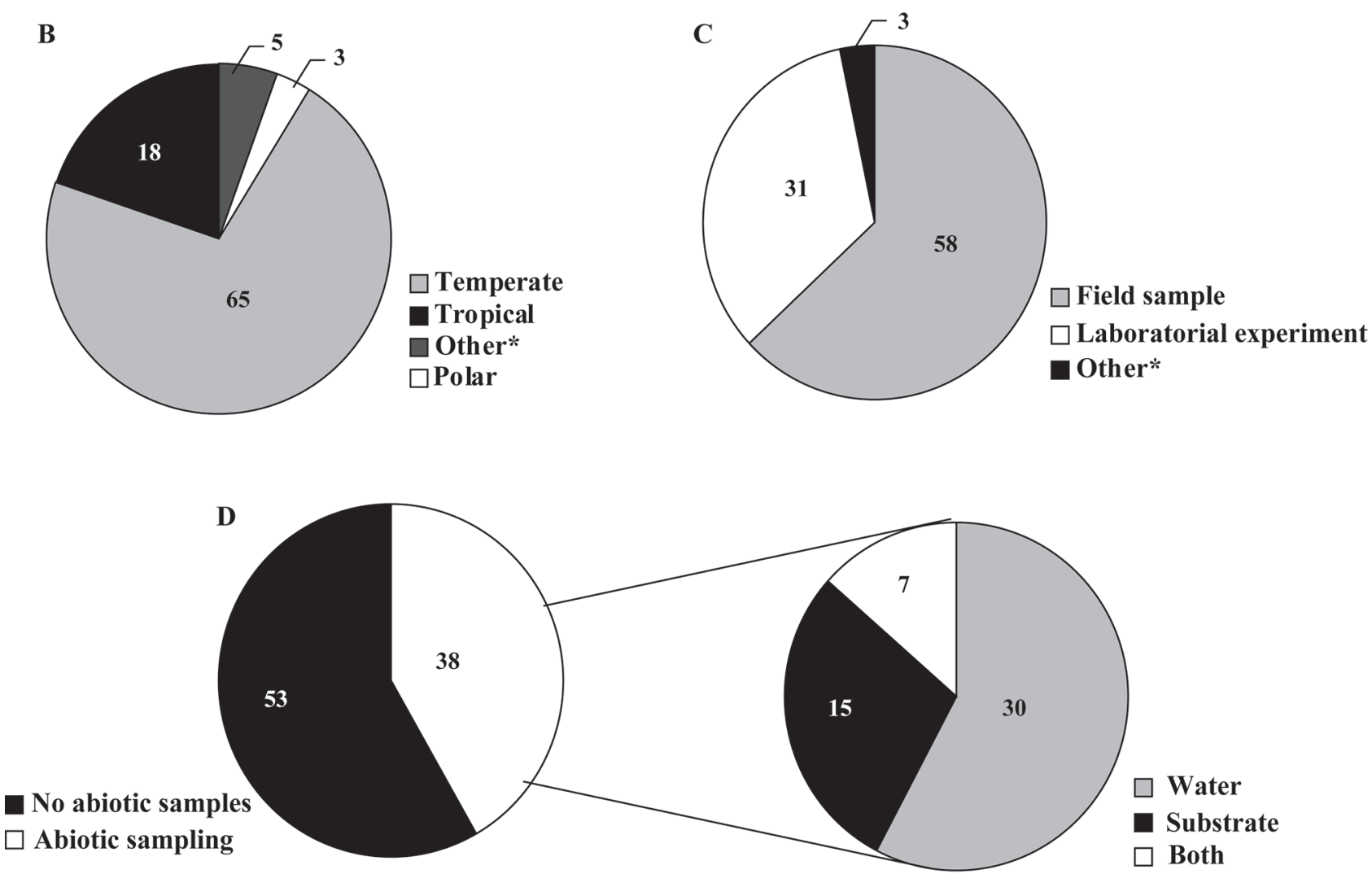

Figure 2. A. Frequency of studies' occurrences per continent. B. Pie chart of relative percentage frequency of climate zones of studies (Temperate, Tropical and Polar). The symbol $\left({ }^{*}\right)$ is related to the category "Other" and includes studies using laboratorial clonal samples or biomass for human consumption. C. Pie chart of relative frequency of types of studies. The symbol $\left({ }^{*}\right)$ is related to the category "Other" and includes studies that employed biomass for human consumption. C. Pie chart of relative frequency of abiotic sampling between studies. The fraction of articles that included abiotic data is also partitioned in relative frequency of occurrence. 


\section{Giulia Burle Costa, Gabrielle Koerich, Bruna de Ramos, Fernanda Ramlov, Begoña Martínez-Crego, Monya M. Costa, Dora Jesus, Rui O.P. Santos and Paulo A. Horta Jr.}

from polar areas can be redistributed via physical, chemical, geochemical and biological process (Potapowicz et al. 2019). Moreover, significant concentrations of pollutants, such as pesticides, polycyclic aromatic hydrocarbons and heavy metals from anthropogenic sources already have been reported in Antarctica (Potapowicz et al. 2019). Therefore, considering the increased potential for pollution, the monitoring of contamination by heavy metals in these regions should be intensified. Additionally, climate change will modify the physical and chemical characteristics of seawater (IPCC 2014), and the remobilization of stored pollutants can increase the toxic effects of these metals to organisms (Nikinmaa 2013).

Most studies surveyed here were a systematic characterization of heavy metal contents in algal samples collected in situ (63.74\%), followed by experimental evaluations of heavy metal exposure (34.07\%). Interestingly, three studies (3.30\%) did not use field samples and instead explored the presence of metals in food resources (Fig. $2 \mathrm{C}$ ). None of the compiled studies performed seasonal monitoring or replications, and only 21 presented seasonal data or replications within the same season, but in different years. Specifically, only five studies presented annual and seasonal replications in their sampling (Tab. 3).

Table 2. Frequencies of studies developed in each country according to the present database $(n=91)$. Countries with the same frequency in the database were listed in the same line, and the correspondent number represents the individual effort of each listed country. Frequency of efforts is presented in decreasing order.

\begin{tabular}{|c|c|}
\hline Countries & $\begin{array}{c}\text { Frequency of } \\
\text { studies }\end{array}$ \\
\hline Brazil & 14 \\
\hline Chile & 7 \\
\hline India, Mexico & 6 \\
\hline England & 5 \\
\hline Australia, Egypt & 4 \\
\hline Saudi Arabia, China, Spain, Irish, Italy, Turkey & 3 \\
\hline $\begin{array}{c}\text { Polonia, Antarctica, South Korea, United States of } \\
\text { America, Malaysia, United Kingdom }\end{array}$ & 2 \\
\hline $\begin{array}{c}\text { Algeria, Denmark, Finland, France, Greece, Yemen, } \\
\text { Mauritius Islands, Indonesia, Iran, Libya, Morocco, } \\
\text { Pakistan, Portugal, Romania, Tunisia }\end{array}$ & 1 \\
\hline
\end{tabular}

Table 3. Frequency of studies considering seasonality of the field sampling in the experimental design ( $\mathrm{n}=21$ studies). Correlation between columns and lines indicate the frequency of simultaneous sampling in indicated seasons.

\begin{tabular}{|c|c|c|c|c|}
\hline & Spring & Summer & Autumn & Winter \\
\hline Spring & 0 & & & \\
\hline Summer & 7 & 1 & & \\
\hline Autumn & 4 & 3 & 1 & \\
\hline Winter & 3 & 1 & 1 & 0 \\
\hline All seasons & $\mathbf{5}$ & & & \\
\hline
\end{tabular}

Regarding heavy metals' characterization in the abiotic component (including substrate and/or water sampling), 53 studies (58.24\%) did not measure these parameters in the field, when sampling, or in experimental design (Fig. 2D). In turn, 30 studies (32.97\%) measured concentrations of heavy metals in seawater, and 15 (16.48\%) in the substrate, but only seven studies ( $7.69 \%$ ) considered both components simultaneously (Fig. 2D). The lack of data about the concentration of metals in the field makes difficult the evaluation of heavy metals' influence in organisms, as there is possibly an established relationship between the overall availability of metals in the environment and the fraction of these metals that is available to be assimilated by macroalgae.

\section{Biological and ecotoxicological parameter categories}

The data from the 91 analyzed studies included investigations of heavy metals' impacts in 363 seaweed samples, with 225 species of 83 genera. Considering the distribution among groups, there is a higher frequency of studies with Phaeophyceae (131), followed by Rhodophyta (117) and Chlorophyta (108) (Fig. 3A). However, when grouping the data by genera, there is a higher diversity of Rhodophyta (36 genera, 43.37\%), followed by Phaeophyceae (30 genera, 36.14\%) and Chlorophyta (17 genera, 20.48\%). Besides the high representation of Rhodophyta, the most representative genus was Sargassum, with 33 studies (22 species), followed by Ulva with 31 studies (nine species) and Enteromorpha with 23 studies (eigth species) (Fig. 3B). Results of the frequency of genera is presented in Table 4. The complete list of species and respective frequency of occurrences is presented in Table $\mathrm{S} 1$ in supplementary material.

The compiled data shows a high divergence between species studied, and 159 species (70.67\%) were studied only once. Curiously, the species Ulva lactuca was present 16 times in the studies and was the only species with this high representation, contributing to the higher frequency of its genus. Considering that many species were employed in less studies, further investigations to evaluate the most studied biological models were done at the genera level, and results are presented in the following section 3.5. Investigations considering the impacts of heavy metals at the ecosystem level were absent in the present review. In contrast, investigations at the individual or population levels together represented $83.7 \%$ of articles, with 39 and 38 studies, respectively (Fig. 4A).

Analyzing the other proposed parameters in the biological category (Tab. 1), there was a small but significant effort in the replication of physiological, morphological and ecological descriptors compared to ecotoxicological descriptors (Tab. 1). In the ecotoxicological category, the majority of studies focused on finding recommended species to perform bioaccumulation analyses ( 85 studies or 
A

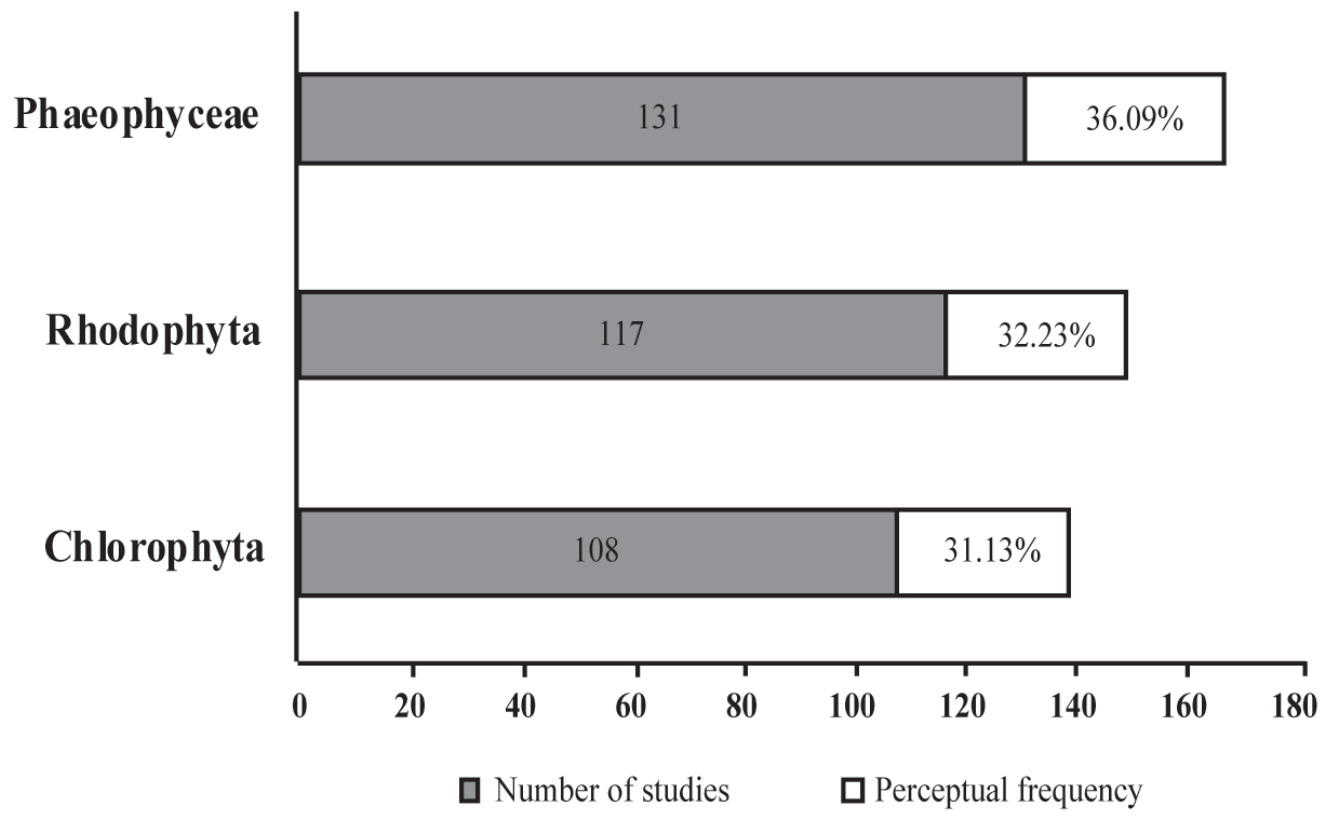

B

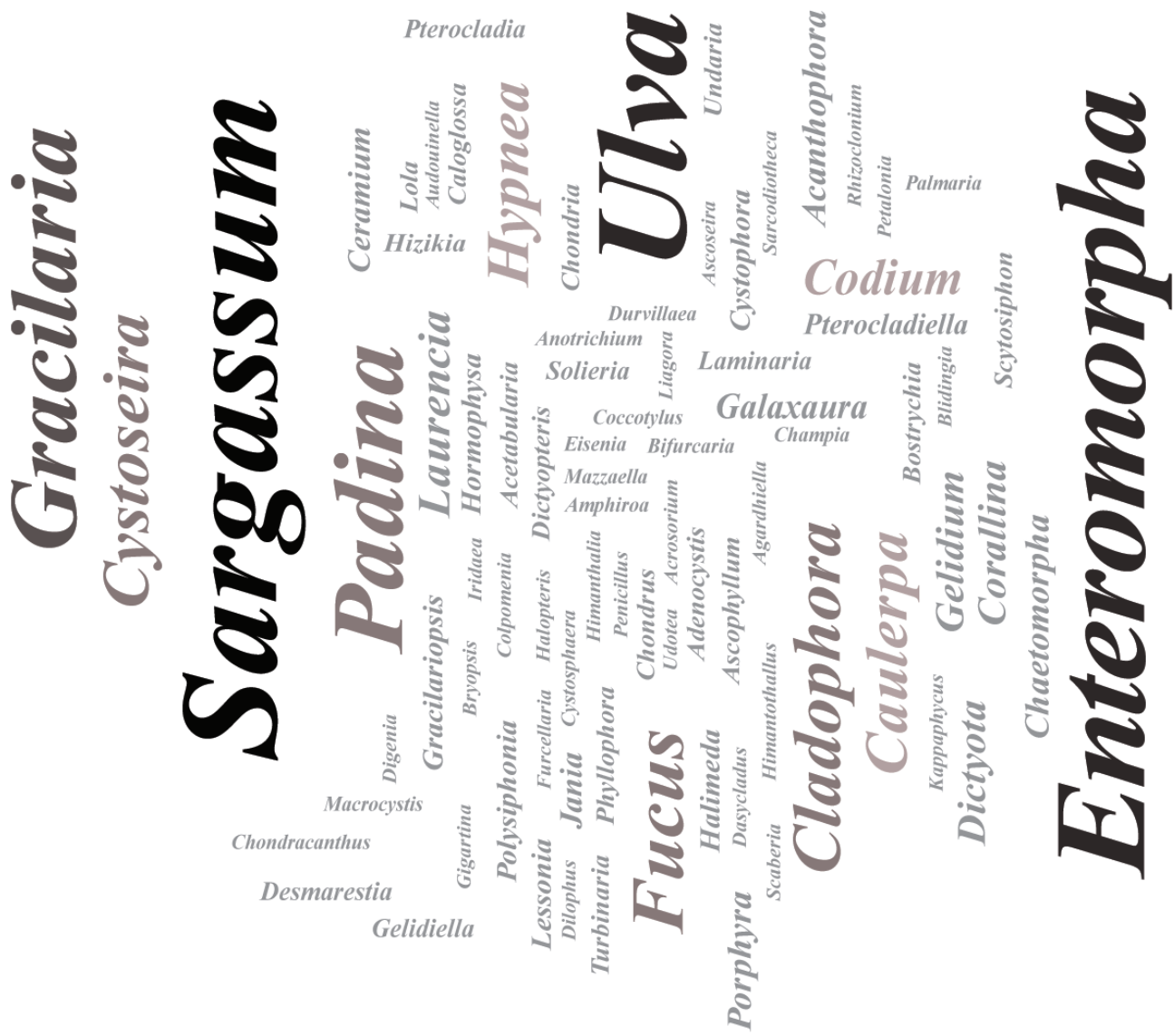

Figure 3. A. Relative frequency (numerical and percentage) of citations per algae group. B. Word cloud of relative frequency of citations for algae genera. Letters size and line strength indicate the proportional frequency of each algae genera. 


\section{Giulia Burle Costa, Gabrielle Koerich, Bruna de Ramos, Fernanda Ramlov, Begoña Martínez-Crego, Monya M. Costa, Dora Jesus, Rui O.P. Santos and Paulo A. Horta Jr.}

93.41\%) (Fig. 4B, Bi). The application of biomarkers and/or bioindicators, when put together, were also represented in studies, but not with the same frequency of bioaccumulation, which was the descriptor most analyzed in the studies.

Furthermore, in the biological category, the descriptors most investigated were physiological descriptors (31 studies or $34.07 \%$ ), followed by morphological (14 studies or $15.38 \%$ ), and ecological descriptors (eigth studies or $8.79 \%$ ) (Fig. 4B). As for physiological descriptors (selected as described in Table 1), carbon and nutrient uptake were the descriptors less analyzed in studies. In contrast, growth rates and secondary metabolites (i.e. amino acids and phenolic compounds) were the most frequent descriptors, present in 17 and 16 studies, respectively (Fig. 4Bii). Regarding morphological descriptors, Transmission Electron Microscopy (TEM) was the most applied descriptor to investigate structural alterations caused by exposure to heavy metals (12 studies) (Fig. 4B ${ }^{\mathrm{iii}}$ ). However, morphological descriptors were not frequently used in studies to assess heavy metals' impacts, and 77 of them did not include any of these parameters. Moreover, microscopy techniques were most present in investigations of individual or population samples, which is consistent

Table 4. Complete list of genera cited in studies selected in our database ( $\mathrm{n}=91$ articles and 83 genera). The data is organized by algae groups (Chlorophyta, Rhodophyta and Phaeophyceae), and alphabetically ordered. The most frequent genus cited to each algae group is highlighted in bold.

\begin{tabular}{|c|c|c|c|c|c|}
\hline & Genera & Frequency of citation & & Genera & Frequency of citation \\
\hline \multirow[t]{17}{*}{ Chlorophyta } & Acetabularia & 2 & & Kappaphycus & 1 \\
\hline & Blidingia & 1 & & Laurencia & 8 \\
\hline & Bryopsis & 1 & & Liagora & 1 \\
\hline & Caulerpa & 12 & & Mazzaella & 1 \\
\hline & Chaetomorpha & 5 & & Palmaria & 1 \\
\hline & Cladophora & 14 & & Phyllophora & 2 \\
\hline & Coccotylus & 1 & & Polysiphonia & 3 \\
\hline & Codium & 9 & & Porphyra & 5 \\
\hline & Dasycladus & 1 & & Pterocladia & 2 \\
\hline & Enteromorpha & 23 & & Rhizoclonium & 1 \\
\hline & Halimeda & 3 & & Scytosiphon & 2 \\
\hline & Lola & 2 & Phaeophyceae & Adenocystis & 2 \\
\hline & Penicillus & 1 & & Ascophyllum & 2 \\
\hline & Pterocladiella & 3 & & Ascoseira & 1 \\
\hline & Turbinaria & 2 & & Bifurcaria & 1 \\
\hline & Udotea & 1 & & Colpomenia & 1 \\
\hline & Ulva & 31 & & Cystophora & 3 \\
\hline \multirow{25}{*}{ Rhodophyta } & Acanthophora & 5 & & Cystoseira & 13 \\
\hline & Acrosorium & 1 & & Cystosphaera & 1 \\
\hline & Agardhiella & 1 & & Desmarestia & 2 \\
\hline & Amphiroa & 1 & & Dictyopteris & 2 \\
\hline & Anotrichium & 1 & & Dictyota & 6 \\
\hline & Audouinella & 1 & & Dilophus & 1 \\
\hline & Bostrychia & 2 & & Durvillaea & 1 \\
\hline & Caloglossa & 2 & & Eisenia & 1 \\
\hline & Ceramium & 4 & & Fucus & 16 \\
\hline & Champia & 1 & & Halopteris & 1 \\
\hline & Chondracanthus & 1 & & Himanthalia & 1 \\
\hline & Chondria & 2 & & Himantothallus & 1 \\
\hline & Chondrus & 2 & & Hizikia & 2 \\
\hline & Corallina & 6 & & Hormophysa & 3 \\
\hline & Digenia & 1 & & Laminaria & 2 \\
\hline & Furcellaria & 1 & & Lessonia & 3 \\
\hline & Galaxaura & 5 & & Macrocystis & 1 \\
\hline & Gelidiella & 2 & & Padina & 23 \\
\hline & Gelidium & 6 & & Petalonia & 1 \\
\hline & Gigartina & 1 & & Sarcodiotheca & 1 \\
\hline & Gracilaria & 21 & & Sargassum & 33 \\
\hline & Gracilariopsis & 3 & & Scaberia & 1 \\
\hline & Hypnea & 12 & & Solieria & 2 \\
\hline & Iridaea & 1 & & Undaria & 2 \\
\hline & Jania & 4 & & & \\
\hline
\end{tabular}


A

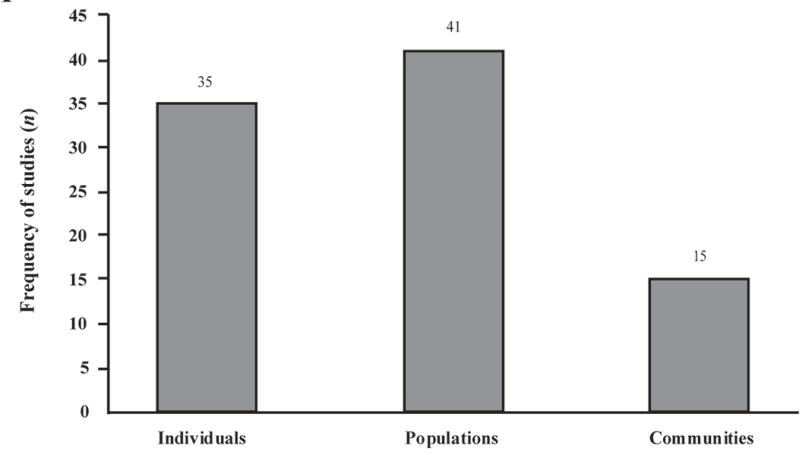

B

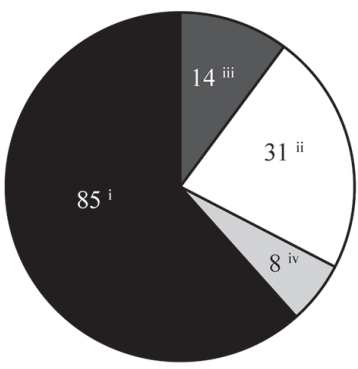

ㅁcology

Ecotoxicology

口Morphology

口Physiology
$\mathbf{B}^{\mathrm{i}}$

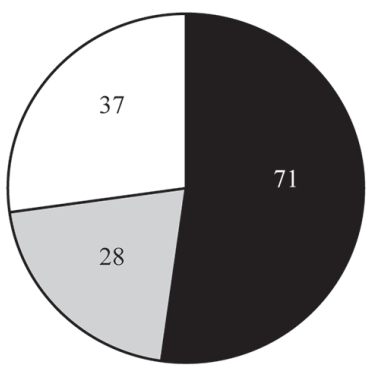

B $^{\text {ii }}$

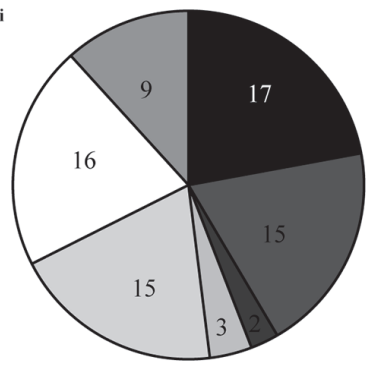

B $^{\text {iii }}$

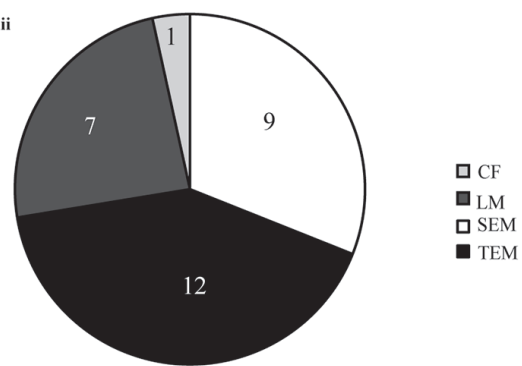

$B^{\text {iv }}$

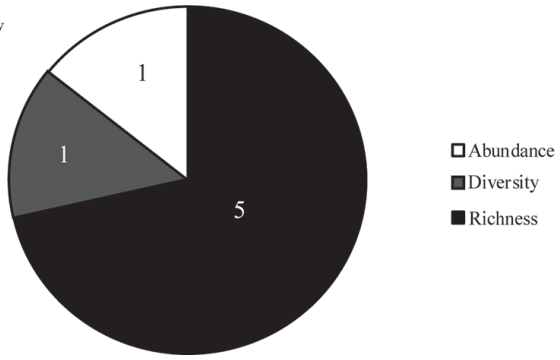

Figure 4. A. Relative frequency (numerical and percentage) of studies per levels of biological organization (from individuals to ecosystem). B. Pie chart of descriptors used per study. Roman numbering (I to IV) in superscript letters indicated the correspondent pie chart for each parameter, where details of relative numerical frequency of each descriptor are presented. $\mathbf{B}^{\mathrm{i}}$. Ecotoxicological parameters. B ${ }^{\mathrm{ii}}$. Physiological parameters. $\mathbf{B}^{\mathrm{iii}}$. Morphological parameters. $\mathbf{B}^{\mathrm{iv}}$. Ecological parameters. 
with observations of the high frequency of studies in these biological levels. Similarly, ecological descriptors (Tab. 1) were absent in more than $90 \%$ of the evaluated studies (Fig. 4B). Additionally, recovery of biomass was not assessed in any study, while richness indices were the ecological parameter with the highest representation, although with only five occurrences (Fig. 4Biv).

The absence of studies in higher levels of biological organization (i.e., community and ecosystem) with poor descriptions of the abiotic components in the compiled data highlights the relevance of using organisms as indicators for monitoring purposes. Clements \& Rohr (2009) highlighted the relevance and necessity of the inclusion of diverse trophic levels to better understand how pollutants impact the environment, considering the effects of toxins moving through a food chain or in a spatial-temporal scale. In addition, there are discrepancies in applications of different biological parameters between analyzed studies, with a higher frequency of use of ecotoxicological descriptors and a low frequency of other parameters' categories.

The low frequency of abiotic evaluations in studies emphasizes the need of a concise correlation between biotic and abiotic descriptors (see previous discussion in section 3.1). The different physicochemical characteristics of seawater (i.e. salinity, $\mathrm{pH}$, and temperature) affect the physiological behavior of photosynthetic organisms, due to alterations in osmotic balance, energetic requirements and nutrient uptake capacity. These parameters change with seasonal characteristics, reinforcing the necessity of monitoring in different seasons to compare the true accumulation of metals related to environmental conditions. A similar recommendation was done by García-Seoane et al. (2018), which observed very few studies with seasonal and long-term temporal monitoring, compromising the characterization of the evolution of environmental pollution and the accumulated impacts in seaweeds. In particular, the majority of compiled studies were conducted in temperate climates, where seasonality is defined with distinct changes in seawater chemical characteristics. Thus, studies giving recommendations for ecotoxicological purposes without previous knowledge about the basal physiological state or the history of contaminants can result in an overestimation of species' potential for monitoring or restauration interests, or even the underestimation of resilience against chronic exposure to heavy metals.

The data concerning contaminated biomass for human consumption, as found in some articles, also deserves attention relative to seasonality, considering the possible increase of heavy metal contents in tissues in different season due to the higher availability of pollutants. The differences between availability and biosorption potential can increase heavy metals' concentrations in algae, inducing neural or hepatic toxic effects in humans according to the season of its collection or cultivation. Moreover, complementary analyses (e.g. meta-analyses comparing temporal-spatial impacts) can lose argumentative strength without considering seasonal variations. Consequently, conclusions made without these considerations can reduce their relevance to conservation policies.

The next step should be the application of similar descriptors between studies, prioritizing relevant parameters to characterize the effects of heavy metals on benthic seaweeds. Studies should not only use ecotoxicological parameters, but also include physiological, morphological and ecological analyses, to better describe the impacts of heavy metals. Additionally, the prioritized descriptors must be accessible both in terms of cost and applicability worldwide, considering the limitations in financial and human resources in developing countries. Those suggestions can help construct a more realistic baseline of heavy metal pollution impacts in marine benthic seaweeds, allowing comparisons in different spatial and temporal scales.

\section{Heavy metals parameters and environmental applications}

The most relevant data for heavy metals measurements in biomass was the characterization of the metal's profile between studies, and the differences between the number of elements in each. More than fifty percent of studies included relative frequencies of four to seven metals. However, there was also a high frequency of monometallic assessments (26.37\%) in the studies (Fig. 5A). Moreover, only one article did a profile with all the nine elements and the "Other" category. These data indicate that, while evaluations of a single element are still common among published studies, multi-parameter studies are becoming more frequent.

The results reveal that $\mathrm{Cu}$ was the most studied element both in monometallic and multi-parameter studies. $\mathrm{Cu}$ concentrations were determined in 74 studies $(80.43 \%)$, followed by Cd (65 studies, $70.65 \%$ ) and Zn (55 studies, $59.78 \%$ ) (Fig. 5B). Aluminum was the least characterized element, and only 8 studies ( $8.70 \%)$ evaluating its concentration. Interestingly, 52 studies $(56.52 \%)$ presented some additional element categorized as "Other" (Fig. 5B), but with low frequency of studies with each observed element. This is relevant because the inclusion of different elements reveals a concern for the source of pollution in a region, or a specific interest in the elements historically recognized as a source of pollution in a local/regional scale. Specifically, mining activities were widely cited as a source of environmental contamination, and the elements added to the evaluated profile reflects the commercial activity developed around the sampling and/or monitoring site (for details of compiled references, see List $S 1$ in supplementary material). Our results are consistent with the results of García-Seoane et al. (2018), following the same trend in frequency and importance of metallic elements, with $\mathrm{Cu}, \mathrm{Zn}, \mathrm{Cd}$ and $\mathrm{Pb}$ as the main investigated elements in biomonitoring studies. 
In respect to the most evaluated elements, we can suggest $\mathrm{Cu}, \mathrm{Cd}$ and $\mathrm{Zn}$ as elements to be considered for comparison between studies. Although $\mathrm{Cu}$ and $\mathrm{Zn}$ are essential micronutrients, small increases in concentrations beyond those physiologically required are toxic (Rai et al. 1981; Nagajyoti et al. 2010). Moreover, these elements are quite common in environments impacted by heavy metals. Considering the natural origin of these elements, $\mathrm{Cd}, \mathrm{Cu}$ and $\mathrm{Zn}$ are present in similar ores, in different proportions according to the ore's category (Nagajyoti et al. 2010). Additionally, they represent an important component of electronic wastes worldwide (Morf et al. 2007; Dimitrakakis et al. 2009; Li et al. 2011). Therefore, the contamination of such elements in marine environments are closely related, and possibly explain why they are evaluated frequently and together.

\section{Evaluation of studies' parameters in representative biological models}

In the present database, Sargassum, Ulva and Enteromorpha were the three most common genera, and as such, we focus on these biological models herein. In sum, 26 studies with Sargassum (33 samples), and 36 studies with Ulva (31 samples) and/or Enteromorpha (23 samples) were compiled for the following analyses and discussion.

The Sargassum (Agardh 1820) genus is widely distributed from tropical to temperate areas (GBIF 2019), and for its cosmopolitan behavior, this genus can be considered a good model to investigate anthropogenic impacts in different regions. The genera Ulva (Linnaeus 1753) and Enteromorpha (Link 1820) are the subject of taxonomic discussions, with proposed reclassifications between them. Currently, the holotype of Enteromorpha genus is recognized as Ulva as the accepted name, and discussions about taxonomic classification of species are still occurring, due to the advancement in molecular systematics (Shimada et al. 2003;

A

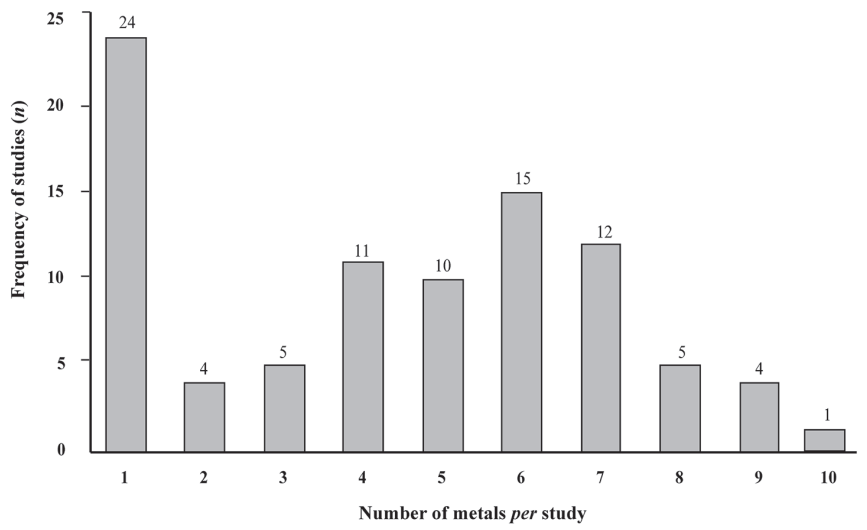

Hayden et al. 2003). To avoid the mistakes and the bias of interpretations, the evaluation of data will encompass all the species of both genera as a unique taxonomical complex, named henceforth as "green complex". The genus Ulva and its synonymies receive special attention because of the environmental phenomenon caused by them called "green tides" (Wang et al. 2015; Bermejo et al. 2019), and they are also recommended for heavy metals monitoring and in vitro evaluation of metallic elements' toxicity (see List S1 in supplementary material). Considering the wide distribution of these models, our database is, therefore, representative of worldwide trends of biological models used in phycological studies. However, it is important to highlight minor differences observed between ours and García-Seoane et al. (2018) results. The authors found Ulva as the most studied genus, while Sargassum was the fourth most relevant genus worldwide in pollution biomonitoring studies. Although there are differences, the similar tendencies of genus and species importance observed between both databases indicate that the differences are likely a consequence of different literature survey methods.

The highest concentration of studies with Sargassum was conducted in Asia (Fig. 6A). Conversely, the green complex had a more equitable distribution among continents, and the highest frequency of studies was in Europe (Fig. 6A). Data regarding countries where studies are developed for both biological models is presented in Table 5. Interestingly, although studies are concentrated in Asia and Europe, when analyzing data of each country, Brazil presented the highest efforts of studies with Sargassum, while Chile focuses in the green complex to evaluate the effect of heavy metals.

Studies were mostly developed in temperate areas (16 with Sargassum and 28 with the green complex) (Fig. 6B). The majority of studies were of field evaluations, characterizing the presence of metal and its concentrations in algal samples (73.08\% for Sargassum and $57.41 \%$ for green complex). Sargassum was a biological model also commonly used

B

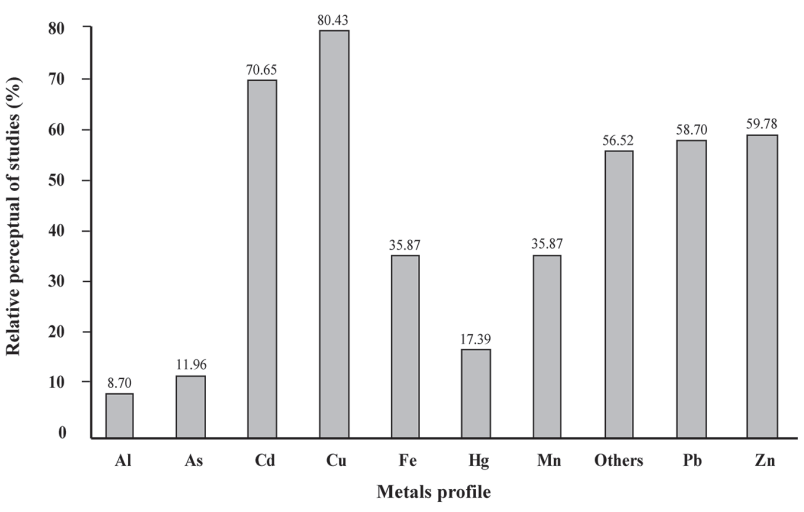

Figure 5. A. Numerical frequency of metallic elements per study ( $\mathrm{n}=91)$, considering the proposed list of nine elements and the "Other" category (n=10 elements per study). B. Relative proportional frequency of each element (Al, $\mathrm{As}, \mathrm{Cd}, \mathrm{Cu}, \mathrm{Fe}, \mathrm{Hg}, \mathrm{Mn}, \mathrm{Pb}, \mathrm{Zn}$ and Other category) evaluated per study. 
for experimental studies ( $26.92 \%$ against $7.41 \%$ of green algae). Both models had one study evaluating the metal's concentration in tissues used as a human food source (Fig. 6C). Seasonality was investigated more frequently in the green complex samples (nine studies) than in Sargassum (three studies) (Tab. 6), and for both models, replication efforts were lower in the winter.

In terms of abiotic parameters, $42.31 \%$ of studies with Sargassum and $50.00 \%$ of studies with the green complex did not present any abiotic data or evaluate heavy metals in seawater or sediments (Fig. 6D, E). These results follow the same tendency of the overall data. Heavy metals' contents in seawater was the most analyzed fraction in both biological models, with $38.46 \%$ in Sargassum and $44.44 \%$ in the green complex studies (Fig. 6F, G). The lack of abiotic data in works with the most studied genus raises concern about the true understanding of heavy metals' effects in studies worldwide. Thus, the influence of abiotic characteristics in the toxic response or accumulative capacity is still poorly understood and must be better evaluated in future studies with these organisms.

Following the tendency of the database, studies that focus on the individual or populational level comprised more than fifty percent for both models (Fig. 7A). However, studies on Sargassum showed a relevant effort in investigations at the community level, with $38.46 \%$ of studies (Fig. 7A). Observing the total data, we observed that Sargassum was present in the majority of studies at the community level and was the most represented genus in this level of biological organization. However, we must acknowledge that Sargassum, as previously stated, is a key group for algal beds as a canopy builder. Thus, due to its wide distribution, its presence in studies which sampled representatives of a community demonstrates the importance of this genus for monitoring actions in higher levels of biological organization. Moreover, the inclusion of multiple species is important to describe the effects of processes influenced by heavy metal pollution on biological interactions. For example, the epiphytic relationship can
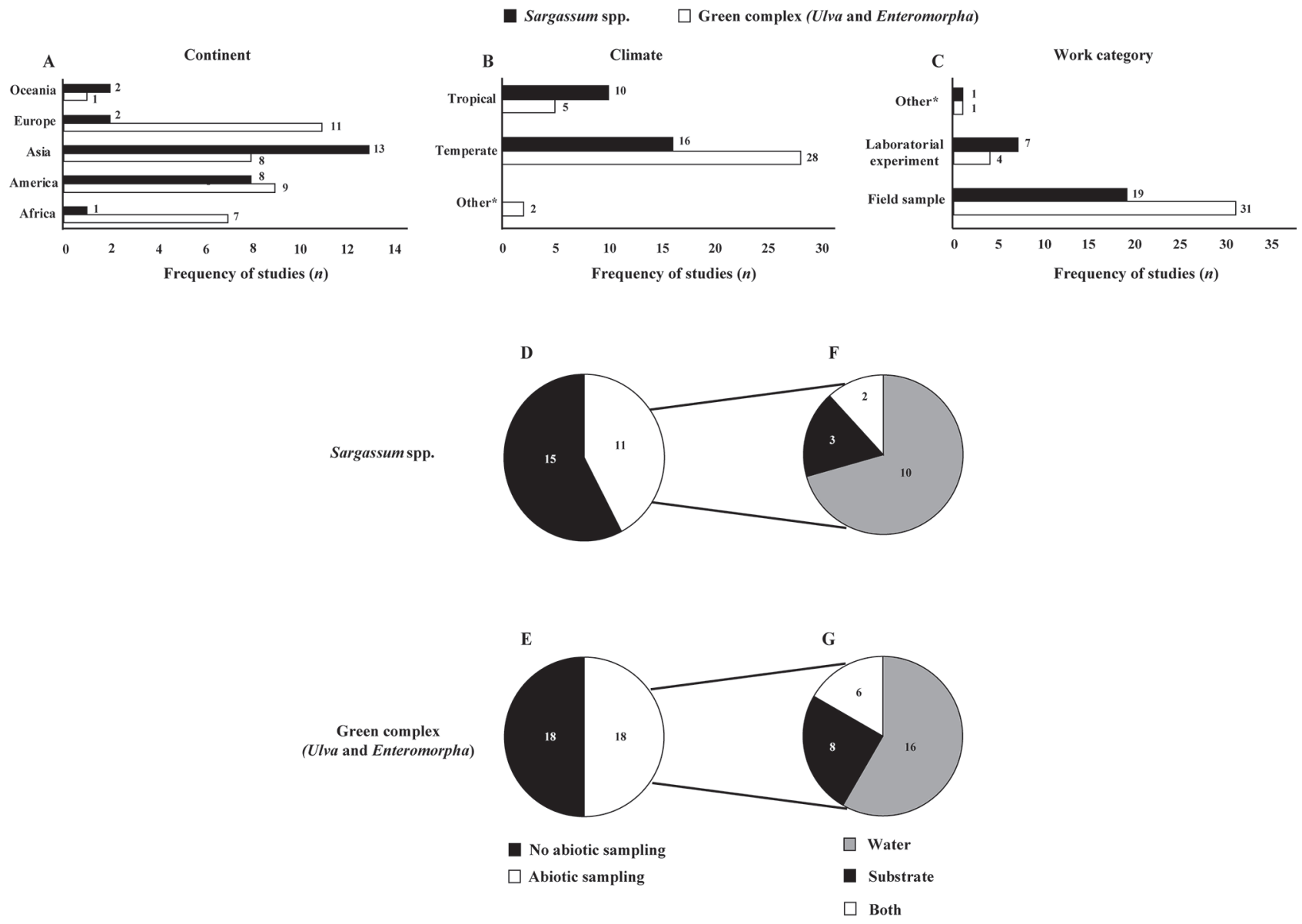

Figure 6. Data for the most used biological models described in the present study, Sargassum and the green complex (Ulva and Enteromorpha genera). A. Relative frequency of studies' efforts per continent. B. Relative frequency of climate zones of studies (Temperate, Tropical and Polar). The symbol $\left({ }^{*}\right)$ is related to the category "Other" and includes studies using laboratorial clonal samples or biomass for human consumption. C. Relative frequency by types of studies. The symbol $\left({ }^{*}\right)$ is related to the category "Other" and includes studies using biomass for human consumption. D and E. Pie chart of relative frequency of abiotic sampling between the studies. F and G. Pie chart of studies' that included abiotic data, partitioned in relative frequency of sampling. 
Table 5. Frequencies of studies developed per country, considering the most studied genera Sargassum (26 studies) and the green complex of Ulva and Enteromorpha (36 studies). Countries are presented in alphabetical order.

\begin{tabular}{|c|c|c|}
\hline Country & Sargassum & Green complex \\
\hline Algeria & 0 & 1 \\
\hline Australia & 2 & 1 \\
\hline Brazil & 5 & 2 \\
\hline Chile & 0 & 5 \\
\hline China & 1 & 0 \\
\hline Egypt & 1 & 4 \\
\hline England & 0 & 1 \\
\hline Finland & 0 & 1 \\
\hline Greece & 1 & 1 \\
\hline India & 5 & 1 \\
\hline Iran & 2 & 2 \\
\hline Irlanda & 0 & 1 \\
\hline Italy & 0 & 2 \\
\hline Malaysia & 1 & 0 \\
\hline Mexico & 3 & 1 \\
\hline Morocco & 0 & 1 \\
\hline Poland & 0 & 1 \\
\hline Romania & 0 & 1 \\
\hline Saudi Arabia & 2 & 2 \\
\hline South Korea & 1 & 1 \\
\hline
\end{tabular}

Table 6. Frequency of studies that consider seasonality in experimental design of field sampling for the most studied biological models: Sargassum genus and the green complex (Ulva and Enteromorpha genera). Correlation between columns and lines indicate the frequency of simultaneous sampling in indicated seasons.

\begin{tabular}{|c|c|c|c|c|}
\hline Sargassum & Spring & Summer & Autumn & Winter \\
\hline Spring & 0 & & & \\
\hline Summer & 1 & 0 & & \\
\hline Autumn & 0 & 0 & 0 & \\
\hline Winter & 1 & 0 & 0 & 0 \\
\hline All seasons & $\mathbf{1}$ & & & \\
\hline Green complex & Spring & Summer & Autumn & Winter \\
\hline Spring & 0 & & & \\
\hline Summer & 3 & 1 & & \\
\hline Autumn & 2 & 2 & 1 & \\
\hline Winter & 1 & 0 & 0 & 0 \\
\hline All seasons & $\mathbf{3}$ & & & \\
\hline
\end{tabular}

be disrupted due to the presence of contaminants (Costa et al. 2019), reinforcing the importance of increasing efforts in evaluations of heavy metals' pollution in higher levels of biological organization.

In the biological and ecotoxicological parameters, the frequency of descriptors for both biological models followed the tendency of the database. Ecotoxicological descriptors were present in $96.15 \%$ of studies with Sargassum and in $94.44 \%$ of studies with the green complex (Fig. 7B, C) and were more frequent than the majority of other biological descriptors. The parameter of bioaccumulation was prevalent in this category, with more than $80 \%$ for both algae (Fig. $\left.7 \mathrm{~B}^{\mathrm{i}}, \mathrm{C}^{\mathrm{i}}\right)$. Differences between the most frequent biological descriptors were found for both models. For Sargassum, the physiological descriptors were more frequent in the studies (seven studies, 26.92\%), with primary metabolites being investigated in more studies (six studies, $23.08 \%$ ), followed by secondary metabolites and growth rates (both with four studies, $15.38 \%$ ) (Fig. 7B, $\mathrm{B}^{\mathrm{ii}}$ ). The green complex had similar results, with physiological descriptors being the most investigated (10 studies, $27.78 \%$ ), but three descriptors had equal frequency between studies, secondary and antioxidant metabolites and photosynthetic rates (with four studies each, $11.11 \%$ ) (Fig. 7C, $C^{\mathrm{ii}}$ ).

Morphological descriptors did not receive much attention in either biological models, compared with the other described parameters. The morphology of Sargassum was evaluated in three studies, and in only one study of the green complex. Transmission Electron Microscopy was the most common parameter assessed between the two biological models, evaluated in two studies with Sargassum (Fig. 7B ${ }^{\mathrm{iii}}$ ) and one study with the green complex. Considering ecological descriptors, richness was present in three and two studies with Sargasum and the green complex, respectively, and both had one study calculating diversity (Fig. 7B ${ }^{\text {iv }}$, 7C $\mathrm{iii}^{\mathrm{ii}}$. Abundance and biomass descriptors were not investigated in neither biological model.

Reinforcing the previous discussion about the relevance of investigations at higher organizational levels, and considering the low correlation with abiotic data, there is a lack of continuity with the application of ecotoxicological concepts in the studies with the widely applied biological models. Besides the wide application of certain descriptors such as bioaccumulation, the absence of descriptors that support these hypotheses and/or monitoring procedures are evident. Especially, the absence and low representation of physiological and ecological descriptors in the database indicates an inaccurate baseline to evaluate the process of resilience and acclimation to disturbances caused by acute or chronic exposure to heavy metals. In light of this, more efforts are needed to evaluate long-term effects of heavy metals' pollution, and also widespread use of descriptors which allow the understanding of patterns and processes driving communities maintenance are needed.

For heavy metals' parameters, considering the number of metallic elements in each study, we observed a high frequency of investigations of multiple metals in studies with Sargassum, more commonly assessing four to six elements (12 studies, 46.16\%) (Fig. 8A). However, studies evaluating monometallic contaminants were still usual for the genus (seven studies, 26.92\%) (Fig. 8A). Similarly, there were many studies of multiple metals in studies with the green complex, with six elements being more addressed (12 studies, 33.33\%) (Fig. 8B). Both biological models had few studies with seven or more elements, and only the green complex presented one study assessing 10 metals. That said, we can unfortunately conclude that the most frequently used biological models follow the tendency to assess metallic 
toxicity in a context of complex multi-pollutants, with simultaneous exposure to different contaminants.

In respect to metallic profile investigations, differences were observed particularly in each biological model. Sargassum was most studied for the effects of $\mathrm{Cd}, \mathrm{Cu}$ and $\mathrm{Pb}$, together comprising $69.23 \%$ of studies (Fig. $8 \mathrm{C}$ ). In turn, for the green complex, $\mathrm{Cu}$ was the most studied element (94.44\%). However, we observed that $\mathrm{Zn}$ and the category "Other" were well represented for this group (both with $75.00 \%$ ) (Fig. 8D). These differences for the most studied elements can indicate differences in application purposes between these models. Contrary to the general trend, the category "Other" was less frequently assessed in Sargassum than the element $\mathrm{Pb}$, possibly indicating that specific metallic elements receive more attention in investigations of this biological model. In contrast, the green complex seems to have a more equitable representation of all models in the database and is less specific for some point-source categories of pollution. This is interesting, considering the previous discussion about the monitoring purposes of major biological groups in the beginning of this section. The application of different models can be an interesting method to construct a scenario of responses to heavy metal pollution, considering a more generic and wide response to different contaminants by the green complex, and more specific and sophisticated physiological responses by Sargassum.

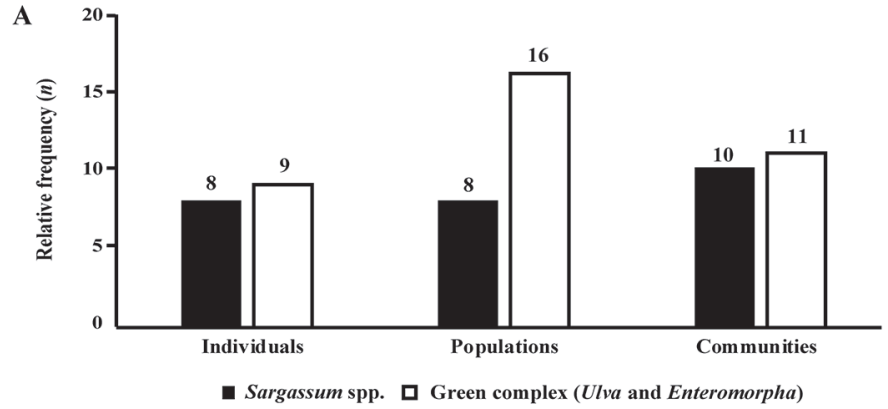

B

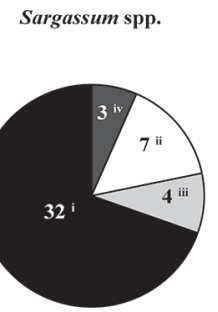

$\square$ Ecology —Ecotoxicology $\square$ Morphology $\square$ Physiology
C

Green complex (Ulva and Enteromorpha)

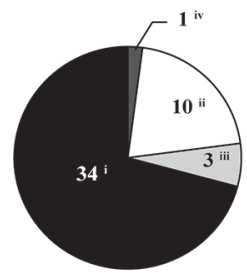

$\square$ Ecology —Ecotoxicology — Morphology $\square$ Physiology
$\mathbf{B}^{\mathbf{i}}$
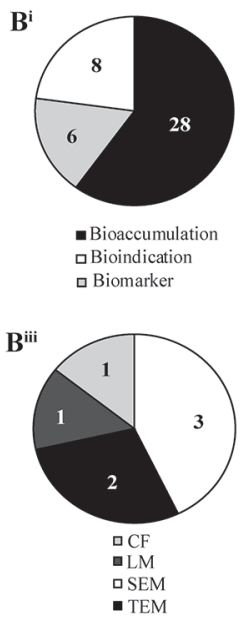

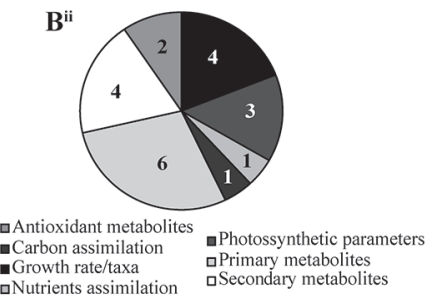

$\mathbf{B}^{\text {iv }}$

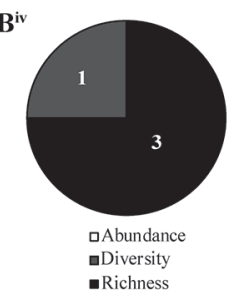

$\mathrm{C}^{\mathrm{i}}$

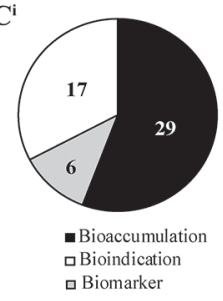

$C^{\text {ii }}$

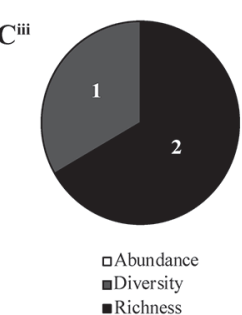

Figure 7. Data for the most used biological models observed in the present study, Sargassum and the green complex (Ulva and Enteromorpha genera). A. Relative frequency of studies per level of biological organization (from individuals to ecosystem). B and C. Pie chart of descriptors applied per study. Roman numbering (I to IV) in superscript letters indicates the correspondent pie chart of each parameter, where details of relative numerical frequency of each descriptor are presented. $\mathbf{B}^{\mathrm{i}}$ and $\mathbf{C}^{\mathrm{i}}$. Ecotoxicological parameters. $\mathbf{B}^{\mathrm{ii}}$ and $\mathbf{C}^{\mathrm{ii}}$. Physiological parameters. $\mathbf{B}^{\mathrm{iii}}$. Morphological parameters. $\mathbf{B}^{\mathrm{iv}}$ and $\mathbf{C}^{\mathrm{iii}}$. Ecological parameters. 


\section{Conclusions}

In the present study, we reviewed a series of scientific studies to assess the main gaps in efforts to replicate parameters and descriptors used to monitor heavy metals' impacts in seaweeds worldwide. The present review was not focused on measurements or discussions about the effectiveness of the observed parameters employed; rather, it sought to highlight the low availability of correlated data between the different studies. The low similarity between parameters employed by studies can limit the strength of comparisons and bring bias to the interpretation of heavy metals' impacts on benthic seaweeds in different regions.

Additionally, the relevance of both Sargassum and the green complex (composed of the genera Ulva and Enteromorpha) for the purpose of environmental monitoring was evident. Still, although these biological models were frequently used in studies, the low similarity among descriptors used limits comparisons of results across studies. The use of specific species with the objective of comparison and monitoring worldwide was not effective, as there was very low representation of the majority of listed species between studies, and most species were mentioned few times. Thus, genera can be a good source for global comparisons to construct a background about
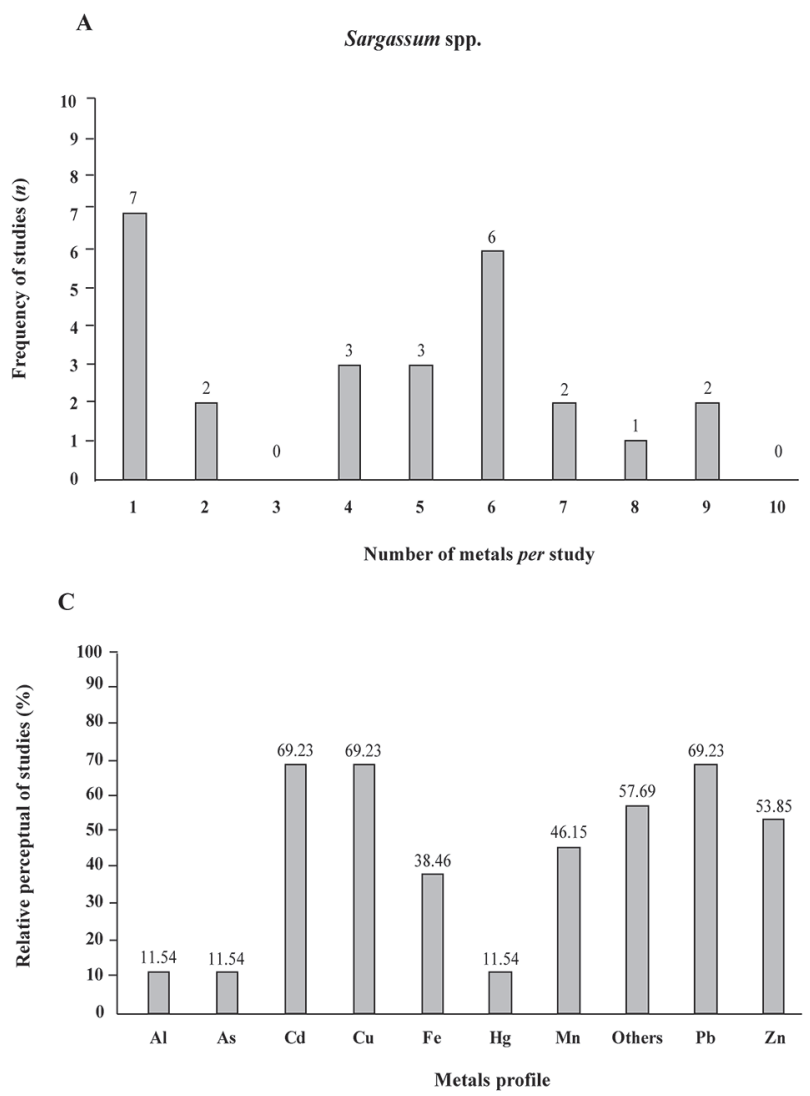

heavy metals' pollution and its impacts in benthic algae. However, considering other species that are important to local communities' structure, or with relevant biological interactions, these species must be studied carefully to be used as representatives in evaluations of the impacts of heavy metals at a local scale. Additionally, many algae species are important as food and economical sources for many traditional cuisines and fisheries. Including these species in monitoring purposes is imperative, considering the potential of biomagnification and bioaccumulation of these elements through the food chain.

The majority of compiled studies had elevated impact factors and are well-indexed in journals with great scientific relevance. Interestingly, our database sampling contrasts with other recent reviews, showing higher representativity of South America in studies than Sánchez-Quiles et al. (2017) results, and following the same continental representativity of García-Seoane et al. (2018) database. The linguistic diversification in the search process showed to be relevant to represent the research of different countries. Nevertheless, the compiled data highlighted important gaps in the parameters used to evaluate heavy metals' impacts, and the divergence in their application between studies and research groups. Similarly, we observed gaps and divergences in sampling procedures highlighted by García-Seoane et al.

B

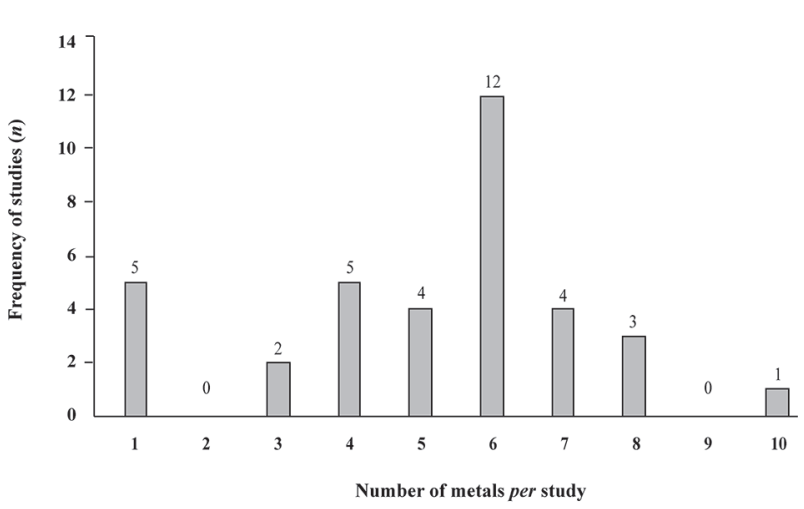

D

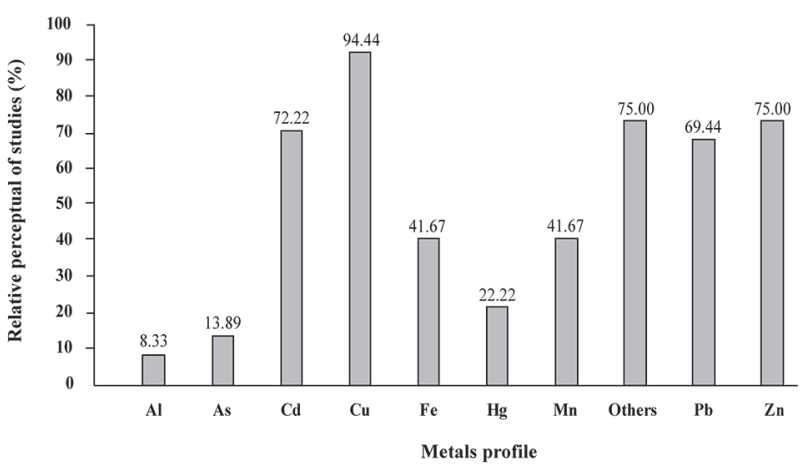

Figure 8. A and B. Numerical frequency of metallic elements per study ( $\mathrm{n}=26$ to Sargassum genus and 36 to green complex), considering the proposed list of nine elements and the Other category ( $\mathrm{n}=10$ elements per study). C and D. Relative percentage frequency of each element (Al, As, Cd, Cu, Fe, Hg, Mn, Pb, Zn and Other category) evaluated per study. 


\section{Giulia Burle Costa, Gabrielle Koerich, Bruna de Ramos, Fernanda Ramlov, Begoña Martínez-Crego, Monya M. Costa, Dora Jesus, Rui O.P. Santos and Paulo A. Horta Jr.}

(2018), reinforcing the need for attention in methodological procedures employed to accurately measure pollution effects in seaweeds.

Although the most used biological models were accompanied by multiple metals evaluations in the studies in which they were employed, the low global effort to make monometallic assays and/or field evaluations, as well as the lack of abiotic evaluations looking to measure the availability of metals in the field, are deficiencies in the analyzed database. These results are not realistic with the increasing complexity of contaminants and with the processes to which chemicals are subjected to in the environment including physical, chemical and geochemical processes. In particular, the trends in oceanic physical and chemical changes, due to the processes of ocean acidification and global warming, can intensify the effects of heavy metals' pollution in seaweeds (Nikinmaa 2013), increasing the lethality of heavy metals' toxicity, causing changes in community structure and losses in ecosystem services. Considering this, multidisciplinary evaluations are suggested, including environmental data of heavy metals' concentrations in diverse parts of the ecosystem (i.e., sediments, seawater, etc.), which are necessary to construct a baseline of pollution at large temporal-spatial scales. Moreover, the inclusion of varied and similar descriptors is necessary to allow comparisons on a global scale, supporting effective actions of conservation and restoration of impacted areas.

The large discrepancy between the environmental problems and the evaluated models may be responsible for ineffectiveness of future initiatives focused on monitoring and restoration of degraded areas. Furthermore, the sporadic use of some techniques, especially of evaluations of cellular structures and physiological processes, reveals weaknesses in suggesting a species/genus as biomarkers. Additionally, without aspects related to ecological parameters, such as abundance, richness and diversity, arguments supporting biomonitoring actions are inconsistent. Therefore, we suggest focusing efforts in employing the same descriptors across studies to evaluate heavy metals' impacts, and in standardizing procedures to describe possible effects of pollution. These standardizations and recommendations for measurements of accumulated heavy metals in biomass and environmental evaluations should follow international parameters. With those precautions, comparisons between measurement results will be more accurate, and together with the use of a precautionary principle for environmental and human security, will allow a proper implementation of policies of management and restoration.

Finally, we also highlight the relevance of widely applying ecological parameters in field evaluations, involving descriptors of population or community dynamics, such as the previously cited indexes of richness, diversity, abundance, and biomass measurements, in the presence of heavy metal pollutants. Those descriptors are key factors for assessing ecosystem services, such as carbon and oxygen balances. Also, the estimation of biomass production can help initiatives of monitoring, by evaluating the structure of food webs, and consequently, the recruitment of associated fauna or management of fisheries sources. The understanding of main gaps in descriptors and parameters, as proposed in the present literature review, can contribute for the future selection of biological models and the discussion about the relevance of data produced to date, stimulating new evaluations of the effectiveness for each parameter. All these directions and efforts are necessary for a well-organized and global effort focused in marine resources conservation, preserving ecosystem functioning and human well-being.

\section{Acknowledgements}

We thank the financial support from the Conselho Nacional de Desenvolvimento Científico e Tecnológico (CNPq), Coordenação de Aperfeiçoamento de Pessoal de Nível Superior (CAPES), FAPESC-Fundação de Amparo à Pesquisa e Inovação do Estado de Santa Catarina, FAPESPFundação de Amparo à Pesquisa e Inovação do Estado de São Paulo and Fundação Boticário. Giulia Burle Costa acknowledge to the Center of Marine Science, Algarve University (Portugal), for the Sandwich period. We also thank Walter A. Rich IV for English grammar review.

\section{References}

Agardh CA .1820. Species algarum rite cognitae, cum synonymis, differentiis specificis et descriptionibus succinctis. Berling, Ex. Officina Berlingiana, Lund.

Arenas-Sánchez A, Rico A, Vighi M. 2016. Effects of water scarcity and chemical pollution in aquatic ecosystems: State of the art. Science of the Total Environment 572: 390-403.

Bermejo R, Heesch S, Mac Monagail M, et al. 2019. Spatial and temporal variability of biomass and composition of green tides in Ireland. Harmful Algae 81: 94-105.

Blaby-Haas CE, Merchant SS. 2017. Regulating cellular trace metal economy in algae. Current Opinion in Plant Biology 39: 88-96.

Cardoso PG, Raffaelli D, Lillebø AI, et al. 2008. The impact of extreme flooding events and anthropogenic stressors on the macrobenthic communities' dynamics. Estuarine, Coastal and Shelf Science 76: 553-565.

Carmo FF, Kamino LHY, Junior RT, et al. 2017. Fundão tailings dam failures: the environment tragedy of the largest technological disaster of Brazilian mining in global context. Perspectives in Ecology and Conservation 15: 145-151.

Chakraborty S, Bhattacharya T, Singh G, Maity JP. 2014. Benthic macroalgae as biological indicators of heavy metal pollution in the marine environments: A biomonitoring approach for pollution assessment. Ecotoxicology and Environmental Safety 100: 61-68.

Clarivate Analytics. 2018. Journal Citation Reports. New York, International Scientific Information, Clarivate Web of Science. https://clarivate.com/ webofsciencegroup/solutions/journal-citation-reports/. 11 Mar. 2019.

Clements WH, Rohr JR. 2009. Community responses to contaminants: using basic ecological principles to predict ecotoxicological effects. Environmental Toxicology and Chemistry 28: 1789-1800.

Contreras-Porcia L, Meynard A, López-Cristoffanini C, et al. 2017. Marine metal pollution and effects on seaweed species. In: Krumar M, Ralph P. (eds.) Systems Biology of Marine Ecosystems. Cham, Switzerland, Springer International Publishing. p. 35-48. 


\section{A review of common parameters and descriptors used in studies of the impacts of heavy metal pollution on marine macroalgae: identification of knowledge gaps and future needs}

Costa GB, Ramlov F, Koerich G, et al. 2019. The effects of mining tailings in the physiology of benthic algae: Understanding the relation between mud's inductive acidification and the heavy metal's toxicity. Environmental and Experimental Botany 167: 103818. doi: 10.1016/j. envexpbot.2019.103818

Davis TA, Volesky B, Mucci A. 2003. A review of the biochemistry of heavy metal biosorption by brown algae. Water Research 37: 4311-4330.

Dimitrakakis E, Janz A, Bilitewski B, Gidarakos E. 2009. Determination of heavy metals and halogens in plastics from electric and electronic waste. Waste Management 29: 2700-2706.

Easterling DR, Meehl GA, Parmesan C, et al. 2000. Climate extremes: Observations, modeling, and impacts. Science 289: 2068-2074.

Gao G, Liu Y, Li X, et al. 2017. Expected $\mathrm{CO}_{2}$-induced ocean acidification modulates copper toxicity in the green tide alga Ulva prolifera. Environmental and Experimental Botany 135: 63-72.

García-Seoane R, Fernández JA, Villares R, Aboal JR. 2018. Use of macroalgae to biomonitor pollutants in coastal waters: Optimization of the methodology. Ecological Indicators 84: 710-726.

Gattuso JP, Magnan A, Billé R, et al. 2015. Contrasting futures for ocean and society from different anthropogenic $\mathrm{CO}_{2}$ emissions scenarios. Science 349: aac4722. doi: 10.1126/science.aac4722.

GBIF. 2019. GBIF: The Global Biodiversity Information Facility. Copenhagen, Global Biodiversity Information Facility. https://www.gbif.org/. 11 Mar. 2019

Harley CDG, Anderson KM, Demes KW, et al. 2012. Effects of climate change on global seaweed communities. Journal of Phycology 48: 1064-1078.

Hatje V, Pedreira RMA, Rezende CE, et al. 2017. The environmental impacts of one of the largest tailing dam failures worldwide. Scientific Reports 7: 10706. doi: 10.1038/s41598-017-11143-x.

Hayden HS, Blomster J, Maggs CA, et al. 2003. Linnaeus was right all along: Ulva and Enteromorpha are not distinct genera. European Journal of Phycology 38: 277-294.

Iluz D, Fermani S, Ramot M, et al. 2017. Calcifying response and recovery potential of the brown alga Padina pavonica under ocean acidification. ACS earth and Space Chemistry 1: 316-323.

IPCC. 2014. Climate Change 2014: Synthesis Report. In: Core Writing Team, Pachauri RK, Meyer LA. (eds.) Contribution of Working Groups I, II and III to the Fifth Assessment Report of the Intergovernmental Panel on Climate Change. Geneva, Switzerland, IPCC.

Lambers H, Chapin FS, Pons TL. 2008. Plant Physiological Ecology, 2nd edn. New York, NY, Springer.

Lawes JC, Clark GF, Johnston EL. 2016. Contaminant cocktails: Interactive effects of fertiliser and copper paint on marine invertebrate recruitment and mortality. Marine Pollution Bulletin 102: 148-159.

Li J, Duan H, Shi P. 2011. Heavy metal contamination of surface soil in electronic waste dismantling area: Site investigation and sourceapportionment analysis. Waste Management \& Research 29: 727-738.

Link HF. 1820. Epistola ad virum celeberrimum Nees ab Esenbeck de algis aquaticis, in genera disponendis. In: Esenbeck CG. (eds.) Horae physicae berolinenses. Bonnae [Bonn]: Sumtibus Adolphi Marcus. Bruschke, Berlin, Nova Acta Academiae Caesareae LeopoldinoCarolinae Germanicae Naturae Curiosorum. p. 1-8.

Linnaeus C. 1753. Species plantarum, exhibentes plantas rite cognitas, ad genera relatas, cum differentiis specificis, nominibus trivialibus, synonymis selectis, locis natalibus, secundum systema sexuale digestas. In: Linnaeus C, Willdenow KL, Link HF, Dietrich A. (eds.) Species plantarum, exhibentes plantas rite cognitas, ad genera relatas, cum differentiis specificis, nominibus trivialibus, synonymis selectis, locis natalibus, secundum systema sexuale digestas. Estocolm, Impensis Laurentii Salvii, Holmiae. p. 561-1200.

Martín-Martín A, Orduna-Malea E, Thelwall M, Delgado López-Cózar E. 2018. Google Scholar, Web of Science, and Scopus: A systematic comparison of citations in 252 subject categories. Journal of Informetrics 12: 1160-1177.
MEA. 2005. Ecossystem and humam well-being. Washington D. C., Island Press. Morf LS, Tremp J, Gloor R, et al. 2007. Metals, non-metals and PCB in electrical and electronic waste - Actual levels in Switzerland. Waste Management 27: 1306-1316.

Nagajyoti PC, Lee KD, Sreekanth TVM. 2010. Heavy metals, occurrence and toxicity for plants: A review. Environmental Chemistry Letters 8: 199-216.

Nikinmaa M. 2013. Climate change and ocean acidification-Interactions with aquatic toxicology. Aquatic Toxicology 126: 365-372.

Olivares HG, Lagos NM, Gutierrez CJ, et al. 2016. Assessment oxidative stress biomarkers and metal bioaccumulation in macroalgae from coastal areas with mining activities in Chile. Environmental Monitoring and Assessment 188: 25. doi: 10.1007/s10661-015-5021-5

Peterson HG, Healey FP, Wagemann R. 1984. Metal Toxicity to Algae: A Highly pH Dependent Phenomenon. Canadian Journal of Fisheries and Aquatic Sciences 41: 974-979.

Potapowicz J, Szumińska D, Szopińska M, Polkowska Ż. 2019. The influence of global climate change on the environmental fate of anthropogenic pollution released from the permafrost. Science of the Total Environment 651: 1534-1548.

R Development Core Team. 2018. R: A Language and Environment for Statistical Computing. Austria, R Found Stat Comput Vienna. https:// www.r-project.org/.

Rai LC, Gaur JP, Kumar HD. 1981. Phycology and heavy metal pollution. Biological Reviews 56: 99-151.

Sales M, Cebrian E, Tomas F, Ballesteros E. 2011. Pollution impacts and recovery potential in three species of the genus Cystoseira (Fucales, Heterokontophyta). Estuarine, Coastal and Shelf Science 92: 347-357.

Sampaio R, Mancini M. 2007. Estudos de revisão sistemática: um guia para síntese criteriosa da evidência científica. Revista Brasileira de Fisioterapia 11: 83-89.

Sánchez-Quiles D, Marbà N, Tovar-Sánchez A. 2017. Trace metal accumulation in marine macrophytes: Hotspots of coastal contamination worldwide. Science of the Total Environment 576: 520-527.

SCImago. 2018. Retrieved Date you Retrieve. SCImago Journal \& Country Rank. Madrid, Consejo Superior de Investigaciones Científicas (CSIC). http://www.scimagojr.com. 13 Mar. 2019.

Segura FR, Nunes EA, Paniz FP, et al. 2016. Potential risks of the residue from Samarco's mine dam burst (Bento Rodrigues, Brazil). Environmental Pollution 218: 813-825.

Shimada S, Hiraoka M, Nabata S, et al. 2003. Molecular phylogenetic analyses of the Japanese Ulva and Enteromorpha (Ulvales, Ulvophyceae), with special reference to the free-floating Ulva. Phycological Research 51: $99-108$

Torres MA, Barros MP, Campos SCG, et al. 2008. Biochemical biomarkers in algae and marine pollution: A review. Ecotoxicology and Environmental Safety 71: 1-15.

Wang S-L, Xu X-R, Sun Y-X, et al. 2013. Heavy metal pollution in coastal areas of South China: A review. Marine Pollution Bulletin 76: 7-15.

Wang W-X, Dei RCH. 2001. Metal uptake in a coastal diatom influenced by major nutrients (N, P, and Si). Water Research 35: 315-321.

Wang Z, Xiao J, Fan S, et al. 2015. Who made the world's largest green tide in China?-an integrated study on the initiation and early development of the green tide in Yellow Sea. Limnology and Oceanography 60: 1105-1117.

Wernberg T, Russell BD, Moore PJ, et al. 2011. Impacts of climate change in a global hotspot for temperate marine biodiversity and ocean warming. Journal of Experimental Marine Biology and Ecology 400: 7-16.

Zeng X, Chen X, Zhuang J. 2015. The positive relationship between ocean acidification and pollution. Marine Pollution Bulletin 91: 14-21.

Zhang H, Wang Y, Park T-W, Deng Y. 2017. Quantifying the relationship between extreme air pollution events and extreme weather events. Atmospheric Research 188: 64-79. 